\title{
Erratum to: Hematological profiles of goats naturally infected with Anaplasma ovis in north and northeast Iran
}

\author{
Mahmood Ahmadi-hamedani - Zohreh Khaki • \\ Sadegh Rahbari • Mahnaz A. Ahmadi-hamedani
}

Published online: 29 January 2013

(C) Springer-Verlag London 2013

Erratum to: Comp Clin Pathol (2012) 21:1179-1182

DOI 10.1007/s00580-011-1257-9

The original version of this article inadvertently contained a mistake. The correct affiliation of the first author is Department of Pathobiology, Faculty of Veterinary Medicine, Semnan University of Iran.

The online version of the original article can be found at http://dx.doi.org/ 10.1007/s00580-011-1257-9.

M. Ahmadi-hamedani $(\bowtie)$

Department of Pathobiology, Faculty of Veterinary Medicine,

Semnan University of Iran,

Semnan, Iran

e-mail: ahmadi.hamedani@gmail.com

Z. Khaki

Department of Clinical Sciences, Faculty of Veterinary Medicine,

University of Tehran,

Tehran, Iran

S. Rahbari

Department of Parasitology, Faculty of Veterinary Medicine,

University of Tehran,

Tehran, Iran

M. A. Ahmadi-hamedani

Department of Physiology, Faculty of Animal Sciences,

Natural Resources and Agriculture Sciences of Gorgan University,

Gorgan, Iran 